Research Article

\title{
Mechanical and Formability Evaluation of ST14 Alloys Welded by Friction Stir Welding
}

\author{
Mahmoud Afshari ${ }^{1},{ }^{1}$ Nima Fakhralmobasheri, ${ }^{2}$ Mohammad Reza Samadi, ${ }^{3}$ \\ Amirhossein Alavi, ${ }^{4}$ and Hossein Norozi Foroushani ${ }^{1}$ \\ ${ }^{1}$ Department of Mechanical Engineering, Amirkabir University of Technology, Tehran, Iran \\ ${ }^{2}$ Department of Materials Engineering, Isfahan University of Technology, Isfahan, Iran \\ ${ }^{3}$ Faculty of Mechanical Engineering, Technical and Vocational University (TVU), Borujerd, Iran \\ ${ }^{4}$ Department of Mechanical Engineering, University of Birjand, Birjand, Iran
}

Correspondence should be addressed to Mahmoud Afshari; m.afshari@aut.ac.ir

Received 28 June 2021; Revised 10 July 2021; Accepted 13 July 2021; Published 29 November 2021

Academic Editor: S. Mahdi S. Kolbadi

Copyright (c) 2021 Mahmoud Afshari et al. This is an open access article distributed under the Creative Commons Attribution License, which permits unrestricted use, distribution, and reproduction in any medium, provided the original work is properly cited.

\begin{abstract}
Friction stir welding as one of the modern methods of solid-state welding of steel sheets and aluminum is a highly regarded industry. In these studies, the experimental design and response surface methodology were used. Optimization of experimental conditions and results which are compared with good agreement between the results was observed. The mechanical properties and ductility of welded plates under optimal conditions were studied. Microhardness testing, metallography, tensile testing, and limiting dome height were used to investigate the mechanical properties and formability limit diagram attached, respectively. The results showed that the heat-affected zone is very small and narrow and not easily distinguished from the base metal. In all tests, the failure of the dome height limit in the area was chaos. In all samples welded with the optimal parameters, tensile failure occurred in the base metal region. Turbulence in the region confirms the presence of WC particles. Experimental design and response surface methodology could introduce an optimal state, and the creation of common defects in the FSW process can prevent the binding strength of the guarantee. But due to the lack of proper stirring in the perturbation area in the samples welded with non-optimized parameters, the strength of the connection is not suitable, and samples were broken from the SZ region.
\end{abstract}

\section{Introduction}

Recent advances in the industry, such as welding, on the one hand, and arising new necessities, on the other hand, have encouraged researchers and craftsmen to operate new methods to make an increase in the volume of production. Taking the advantage of friction stir welding (hereinafter called FSW) to connect steel and aluminum sheets has received considerable attention in the automobile industry because this type of welding is very effective. Industries have recently turned their attention to the FSW as one of the ground-braking ways of solid-state welding to connect steel plates. This method can produce high-quality, faultless welding. Plates joined by FSW suffer from some drawbacks, such as a decrease in the strength of welding compared to the base metal which is due to a drop in mechanical properties. Researchers show choosing an instrument with proper speed and diameter between the pin and its shoulder and selecting a proper deviation angle, the direction of the instrument's rotation (clockwise or anticlockwise), the restrain system, and last but not least, the geometry of the instrument contribute to promoting mechanical properties. This method as solid-state welding was innovated in the Welding Institute, UK, in 1991 [1, 2]. Since then, it was reported in [3] that FSW has been used in the joining of Al-alloys. In this context, several studies have been reported on FSW in which the method has been successfully used in welding difficultto-join $\mathrm{Al}$ alloys [4-6]. Furthermore, as pointed out in [7, 8], FSW also has a potential to be used in joining high-temperature materials such as steels. Using this method, 
Jafarzadegan et al. [9] welded steel ST37 to stainless steel 413 while spinning 400 and 800 rotations per minute. They found that samples welded at a high speed showed further extension than those welded at 400 rotations per minute.

Burak and Meran [10] studied the effect of the instrument's rotation ad progressive speed on ferrite steel (AISI 430) using the FSW. They found that everything is being equal, when progress speed is increased by $160 \mathrm{~mm} / \mathrm{min}$, the strength of strain is raised, while in speeds over $160 \mathrm{~mm} /$ min, both experience a decrease. Ueji et al. [11] welded three kinds of steels, including simple-quenched, cold-rolled, and annealed, which all were composed of $64 \%$ carbon and welded through FSW at five different speeds. They found that grain size increases when the rotation speed is increased by 400 rotations per minute. Having similar speed, they observed the quenched sample possessed a wider altered area than annealed and cold-rolled one, which is due to a soft mechanism during the FSW process. The main purpose of optimization is to achieve a welded steel plate with the highest strength. Then, tests such as strain, hardness, and metallography were carried out to evaluate the mechanical properties of the connecting plate. In the following sections, some tests are introduced by which effective parameters on the strength and extension of steel plates are evaluated [12]. So, it contributes to achieving a steel plate with the highest strength and extension. Moreover, formation of a sample with the highest strength and extension was studied through dome limit height test and forming limit diagrams. Finally, a safety zone was offered to select the instrument's rotation and linear movement speed [13].

1.1. Friction Stir Welding (FSW). Friction stir welding was first innovated in the British welding institute as one of the solid-state welding practices in 1991. However, Isab in Sweden was the first company to officially introduce it [14]. A nonconsuming rotating instrument is entered into the heart of the welding point, the area between pin and shoulder of the instrument, and then it enters into the gap between the two adjacent edges and moves along the welding line. Thomas et al. [15] found that triple-slit instruments with spiral pins use less material than cylindrical pins having an equal radius. Their results show that using two-lined instruments, aluminum plates of $50 \mathrm{~mm}$ thickness as well as 6082-T6 aluminum plates of $75 \mathrm{~mm}$ thickness could be welded using a spiral pin (Figure 1).

$$
q=\frac{4 \pi^{2} \alpha \mu P \omega R^{3}}{3 V} .
$$

Mishra and Ma evaluated the maximum temperature developed in the stirred area in the FSW using the welding microstructure (Figure 2) [16].

Li et al. [17] managed to weld a low-content steel M190 through FSW. The most common model to calculate input temperature using the FSW is available in equations (1) and (2). Here, the average input temperature is measured based on surface or time. Here, $q, \mu, \alpha, P, w$, and $v$ as well as $R$ is input power $(\mathrm{W})$, friction index, heat efficiency, instrument's pressure, instrument's rotational speed, linear movement speed, and radius of the shoulder, respectively [18]. Forming limit diagrams serve well to study the behaviour of plates forming. It is drowned by measuring critical strains in the first narrowing, departure, or drawing main strains based on subsidiary ones. When strain in the forming process is drawn at the bottom of the diagram, the forming process is carried out easily. If circular patterns are selected, different states of its deformation, as well as strain conditions, will be similar to diagram B. Therefore, given the value of circles' initial $(d)$, the large $(b)$, and the small diameter $(a)$, the amount of engineering strain will be obtained from equations (2) and (3). To draw the FLD diagram, values related to circles located in the narrowed area are completely or partly refused, and the strain of circles failing to reach the necking point is also considered as trues data [19].

$$
\begin{aligned}
& e_{\text {major }}(\%)=\frac{a-d}{d} \times 100 \\
& e_{\text {minor }}(\%)=\frac{b-d}{d} \times 100
\end{aligned}
$$

1.2. Response Surface Methodology. Response surface methodology was first developed by Crawford in 2006 [21]. Xie et al. [20] define it as follows: response surface methodology is a collection of statistical and mathematical techniques used for modeling and analyzing problems in which the given response variable is affected by several other independent variables. The term "response surface" indicates changes in the response variable need to be considered based on controls [22].

\section{Materials and Methods}

2.1. Samples. Given the application of ST14 plates in the automobile industry due to their plasticity, low-carbon ST14 steel of $1.5 \mathrm{~mm}$ thickness was used in this research. Its composition is available in Figure 3. The ST14 plate was joined to the basal metal through but connection without making any gap. First, the raw steel was cut into pieces of $80 * 160 \mathrm{~mm}$ by a pair of guillotine scissors, and then a rasp was used to flatten its surfaces [23]. A specific fixer was designed and manufactured to connect the steel plate to the basal metal through FSW (Table 1) [24].

To find maximum and minimum linear and rotational movement speeds, with the aid of experimental practices as well as studied resources, an instrument 13 and $3 \mathrm{~mm}$ in shoulder and pin diameter was developed. A cylindrical instrument possessing a shoulder at an interior angle of $15^{\circ}$ and a formless pin was applied (Figure 4). In the present research, a fixture with the dimensions $20 * 400 * 600 \mathrm{~mm}$, an entirely flatbed, and geometrical tolerance of $0.01 \mathrm{~mm}$ was utilized. The bed was first milled to achieve the desired form and then colored [25]. Two entirely flat belts with the dimensions $300^{*} 100^{*} 15$ were used to fasten the plates on the bed. To fasten each belt on the bed, eight M10 bolts were used (Figure 5). 


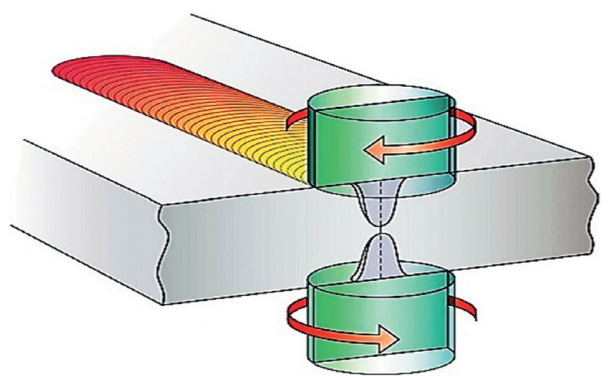

Figure 1: Use of double-sided tools for welding thick aluminum sheets [10].

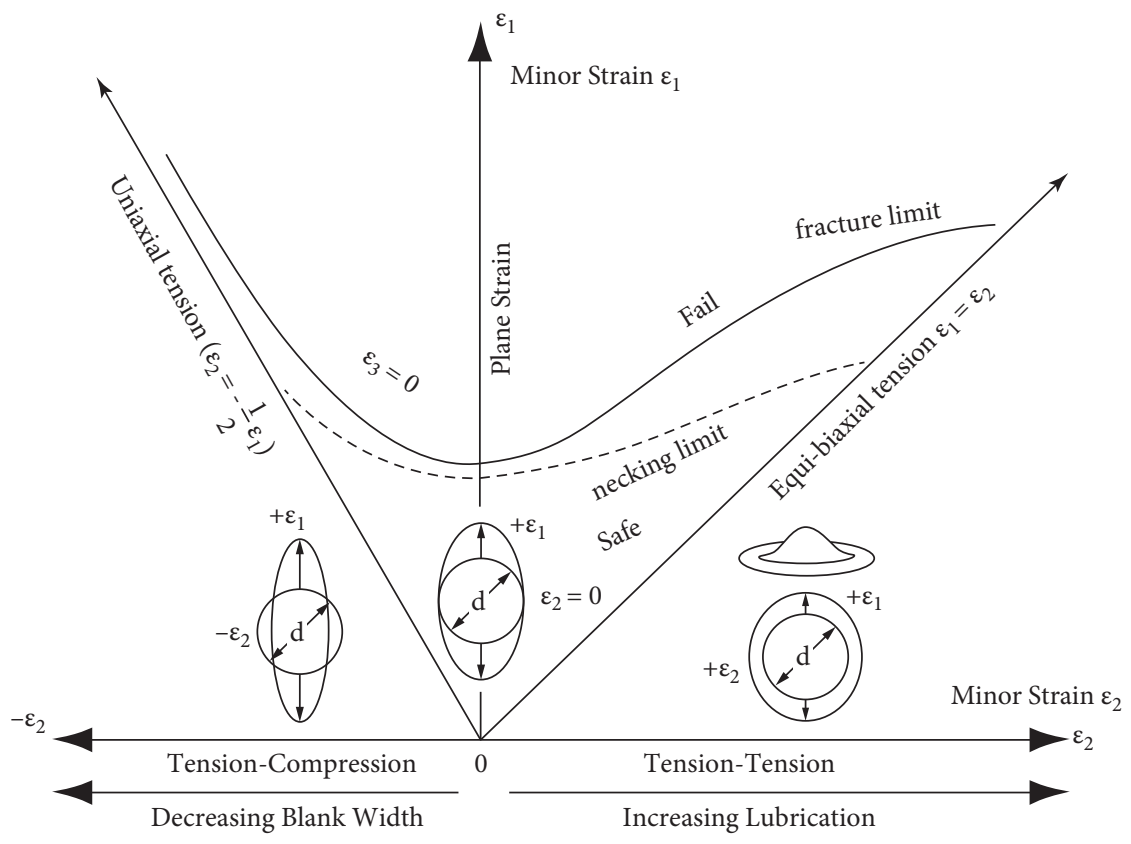

Figure 2: Strain paths in the ductility diagram [16].

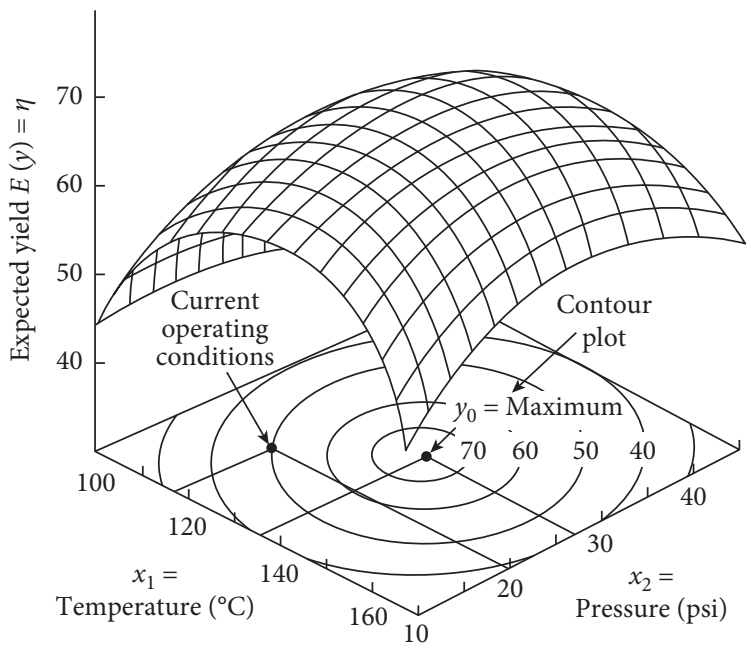

FIgURE 3: The response surface for 2-factor schemes with alignment lines [20]. 
TABLE 1: Chemical composition of ST14 steel (weight percentage).

\begin{tabular}{|c|c|c|c|c|c|c|c|c|c|c|c|c|c|c|}
\hline Grade & C & $\mathrm{Si}$ & $\mathrm{Mn}$ & $\mathrm{P}$ & $S$ & $\mathrm{Ni}$ & Mo & $\mathrm{Cu}$ & $\mathrm{V}$ & W & Co & $\mathrm{Al}$ & Sn & $\mathrm{Pb}$ \\
\hline St14 & 0.04 & 0.01 & 0.23 & 0.007 & 0.006 & 0.03 & 0.01 & 0.03 & 0.002 & 0.003 & 0.004 & 0.055 & 0.007 & 0.003 \\
\hline
\end{tabular}

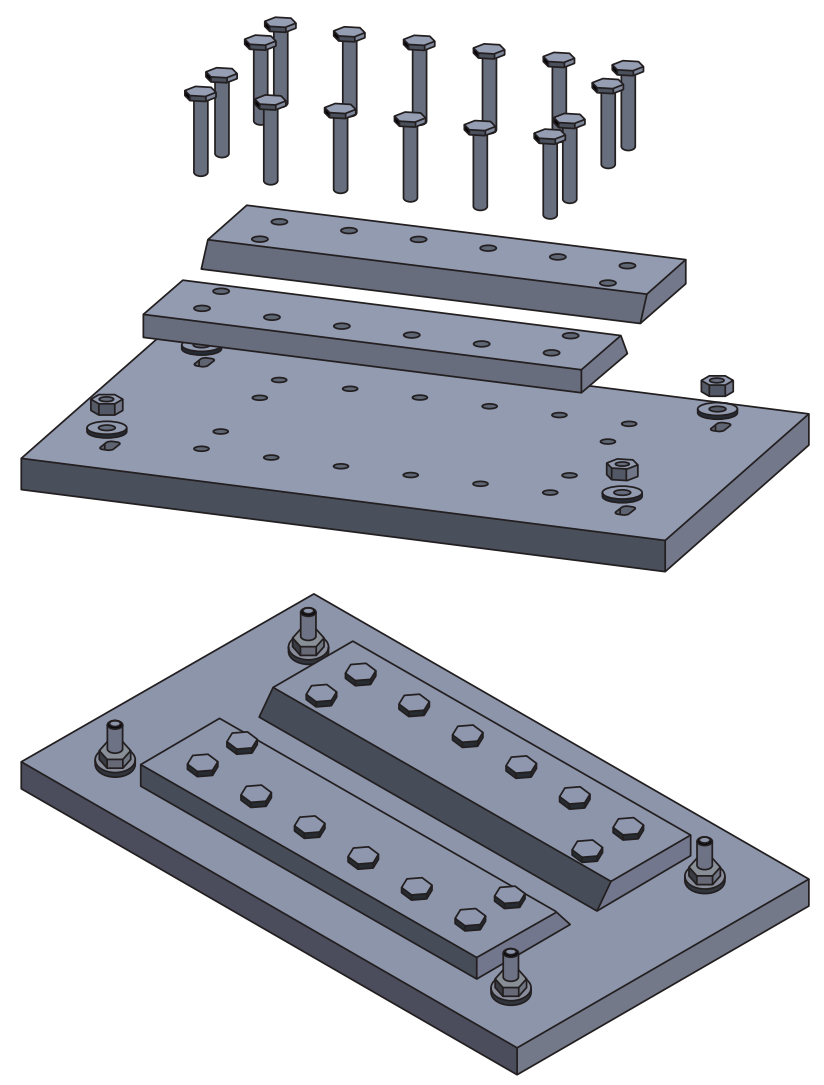

FIGURE 4: Fixtures made to fasten sheets during welding.

\begin{tabular}{|c|c|c|c|}
\hline $\mathrm{D}(\mathrm{mm})$ & $\mathrm{d}(\mathrm{mm})$ & $\mathrm{h}(\mathrm{mm})$ & \multirow{2}{*}{} \\
\hline 13 & 3 & 1.3 \\
\hline 13.5 & 2.5 & 1.3 \\
\hline 14.5 & 3.5 & 1.3 \\
\hline 15.5 & 4.5 & 1.3 \\
\hline
\end{tabular}

FIGURE 5: The tools used in this research along with the parameters used.

\section{Results and Discussion}

In this chapter, research results are discussed. First, findings were studied, and the optimal FSW parameters were obtained after carrying out 29 tests. Then, predicted data and research results were compared. Moreover, microstructures of both basal metal and different areas of the welding point were analyzed. In addition, tensile and hardness tests were done to study the mechanical properties of the joint. Furthermore, a dome limit height test was carried out, and forming limit diagram was drawn for the ST14 plate of $1.5 \mathrm{~mm}$ thickness to study the formation of welded plates. Finally, the instrument's rotation speed, as well as progress speed on the joint, was analyzed, and a safety zone was offered for welding ST14 plates of $1.5 \mathrm{~mm}$ thickness.

3.1. Determining the Optimum Point. In this chapter, a scheme is provided to explain the link between inputs and outputs, and then the optimum strength was measured using 
data of response surface methodology in optimization. Having 4 independent variables and 1 dependent variable, five aspects need to be studied. For the ease to show the diagram of this function in 3-dimension, in each test, two variables were considered constant, and then alterations in the output variable were tested for the two other variables through Design-Expert software (Figure 6).

By increasing the instrument's rotational speed and diameter of its shoulder, on one hand, and a decrease in the linear speed, on other hand, friction increased, which itself contributed to a rise in the input temperature. It is worth noting that these parameters increase friction and input temperature (Figure 7). Although the diameter of the pin has a negligible effect on the objective function, it follows general principles concerning the production of friction and heat. As can be seen from the figures, friction resulting from these parameters is not allowed to increase over the optimum value. The more the friction is increased, the less strong the welding line will be (Figure 8). The reason why this happens will be introduced in the following chapters concerning mythological properties. Data showed it is necessary to select optimal FSW parameters to weld ST14 plates (Table 2).

Welded plates in the optimum state illustrated a final strength ( $305 \mathrm{MPa})$ after doing experimental tests according to alternative, available parameters. Comparing research results and predicted data with $1.09 \%$ error indicates an accuracy of experiments and forecasted strength. The minor error obtained from comparing predicted strength and research results points out the efficiency of the model.

3.2. Evaluating the Microstructure of Welding Metal. It is reasonable to expect ferrite grains to grow and become larger. However, some thermodynamic operations occurred in the region SZ due to rotation of pin and instruments' shoulder which contributes to mechanical retrieval and recrystallization of grains. As a result, grains grow 10-20 times, and finally, mechanical properties of the joint are promoted. Findings showed grains were longer than those in the basal metal in some regions, or at least, their size in the region HAZ was as large as those in the basal metal (Figure 9). Fe- $\mathrm{C}$ diagram in Figure 10 shows the joint structure uses different temperatures. When the input temperature is over the optimal one, carbide-tungsten is disjointed due to high friction and temperature, and then it enters into the stir region, and by affecting joint properties, it contributes to a fall in the strength of the welded point.

\subsection{Evaluating Physical Properties of Connection Tensile Test.} It is a hard situation resulting from strain deformation which initially occurs in the softer area, and then its counteraction to the hard region will transfer the final collapse area to a different place. The first finding obtained from the tensile test is that all welded samples suffered refraction at the joint with the basal metal because of stir created in the structure. As can be seen from microstructure studies, steel ST14 is composed of a heterogeneous structure, composed of ferrite and a few amounts of perlite that is mainly due to low austenite temperature as well as a decrease in cooling during production. Sample A was welded using nonoptimal parameters out of the safe zone. Findings showed that the welding line suffer refraction at stress-strain $132 \mathrm{MPa}$. The strength of sample A was $43.5 \%$ of the basal metal. Moreover, sample a suffered rupture without any increase in its length where the sample and the basal metal welded together because of undesirable parameters. Sample B was shown with desirable parameters in the safety zone and welded using parameters better or worse than the optimal welding state. Findings showed that its tensile strength was $98.3 \%$ of the basal metal. In addition, samples $\mathrm{C}$ and $\mathrm{D}$ were tested using accepted parameters in the safety zone (Figure 11) and welded in an optimal condition. Then, its tensile properties were evaluated compared to optimal parameters.

3.4. Hardness Test. The hardness distribution curve was marked on the profile of welded samples in Figure 12. It is worth noting that the average measure rigidity of the ST14 plate was 91.5. Four samples were welded according to the parameters. Given high friction was created between the instrument's shoulder and pin, so the pin and the instrument suffered an increase in input temperature. It also led to an increase in the hardness of the stir region, and the plasticity of the welding point decreased. Regarding sample $C$, the input temperature was near the optimal value. The structure of region SZ was fine-grained, and its hardness increased due to thermodynamic operations. Concerning sample B, insufficient stir was created between the sample and the basal metal due to lack of heat. Finally, considering parameters of friction stir welding, an optimal state was designed by DOE software under the Montgomery process. A minimum hardness (90-93 HV) was found on the BM area between the progressive region (AS) and where the sample was torn throughout the tensile test (Table 3).

3.5. Limit Dome Height Test. To draw a fair comparison, first, a raw ST14 plate was tested. When the plate was torn, the measurement clock showed $45 \mathrm{~mm}$. As it was expected, plates welded by nonoptimal welding were torn where the plate and the basal metal has been welded [26]. To compare how to form welded and raw plates, these tests were done (Figure 13).

3.6. Forming Limit (FLD) Diagrams. Forming limit tests were carried out to study forming of welded plates of $1.5 \mathrm{~mm}$ thickness according to ASTM E 2218. It was reasonable to expect the sample of thickness $<0.77 \mathrm{~mm}$ to show higher forming than other ones (Figure 14). Moreover, findings showed that samples of $1.17 \mathrm{~mm}$ thickness had the least forming. In addition, samples with different thicknesses were placed between the thickest and the thinnest plates by laser welding (Figure 15).

3.7. Investigating the Effect of Rotation Speed and Instrument's Linear Movement Speed. Data of the response surface methodology, as well as 3-dimensional diagrams of the strength of the welded metal based on different parameters 

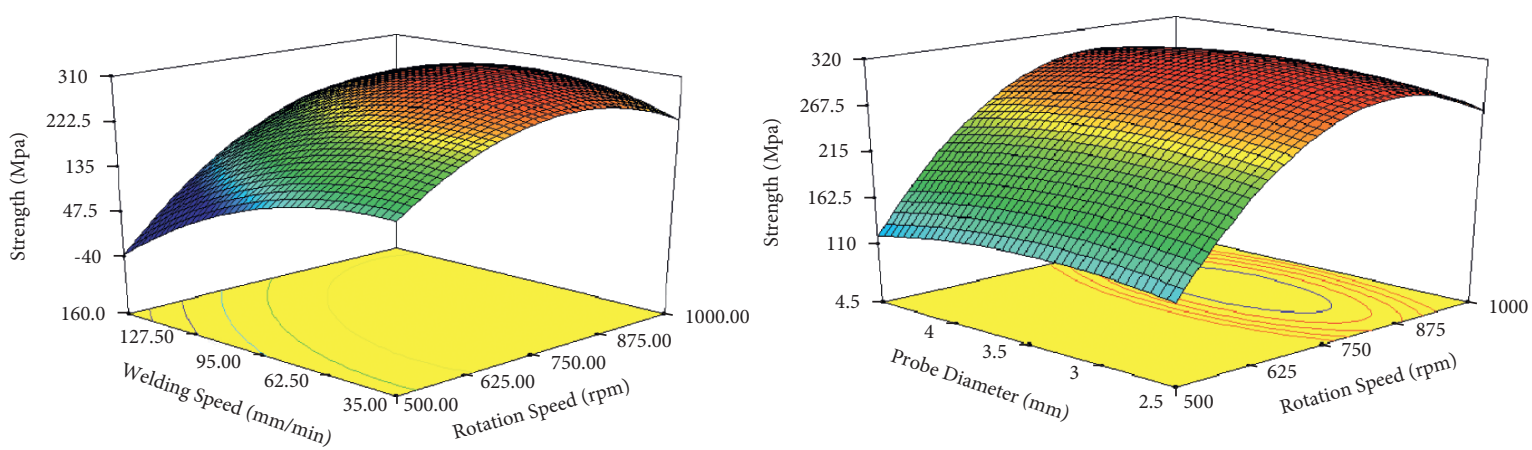

\begin{tabular}{|c|c|c|c|}
\hline Shoulder diameter & Linear motion speed & Shoulder diameter & Pin diameter \\
\hline $14.26 \mathrm{~mm}$ & $78.74 \mathrm{~mm}$ per minute & $14.26 \mathrm{~mm}$ & $3.92 \mathrm{~mm}$ \\
\hline
\end{tabular}

FIGURE 6: Effect of variable parameters of pin diameter and shoulder diameter as well as linear velocity and shoulder diameter on tensile strength of welded sheets.
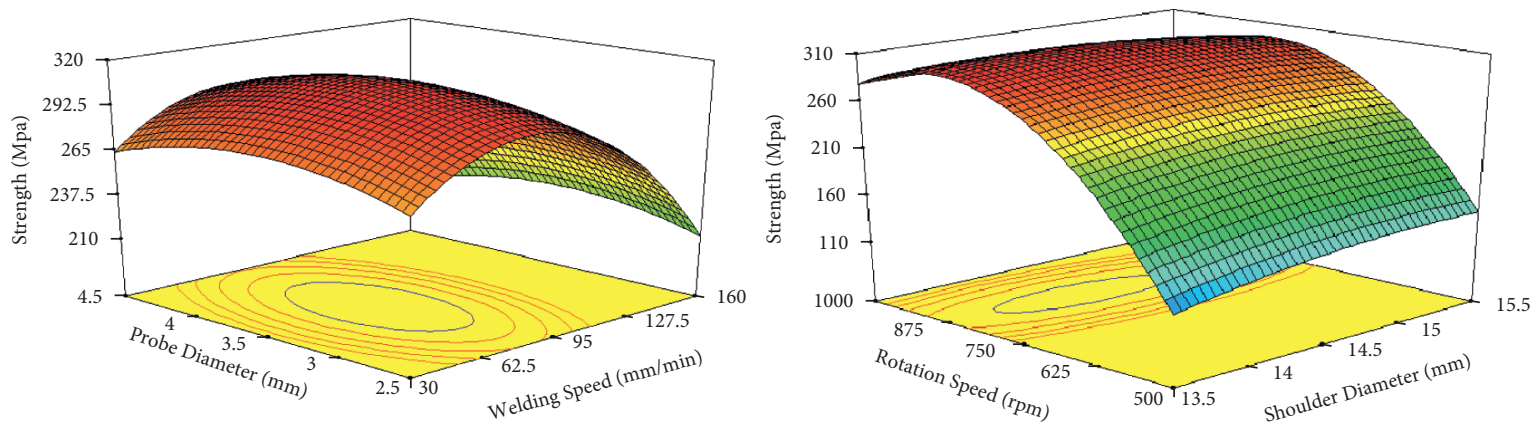

\begin{tabular}{|c|c|c|c|}
\hline Shoulder diameter & Rotational speed & Pin diameter & Linear motion speed \\
\hline $14.2 \mathrm{~mm}$ & $866.32 \mathrm{rpm}$ & $3.92 \mathrm{~mm}$ & $78.74 \mathrm{~mm}$ per minute \\
\hline
\end{tabular}

FIGURE 7: Effect of variable parameters of tool rotational speed and shoulder diameter, as well as linear tool speed and tool pin diameter on tensile strength of welded sheets.
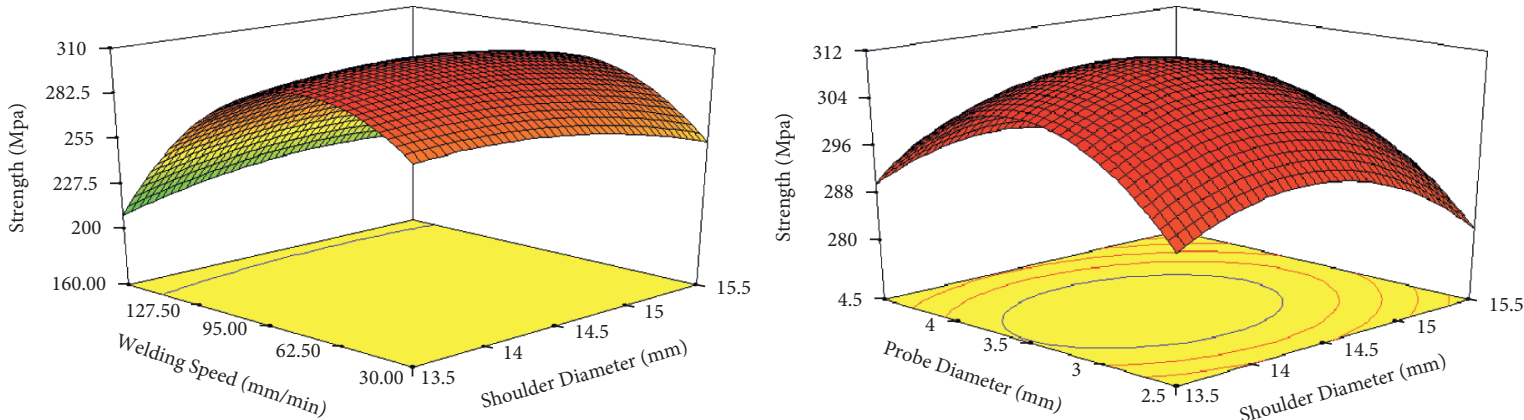

\begin{tabular}{|c|c|c|c|}
\hline Pin diameter & Rotational speed & Linear motion speed & Rotational speed \\
\hline $3.92 \mathrm{~mm}$ & $866.39 \mathrm{rpm}$ & $78.74 \mathrm{~mm}$ per minute & $866.39 \mathrm{rpm}$ \\
\hline
\end{tabular}

FIGURE 8: Effect of variable parameters of tool rotational speed and linear motion speed, as well as rotational speed and pin diameter on tensile strength of welded sheets.

of FSW, show the direct relationship between rotation speed, linear movement speed, the diameter of the shoulder, and diameter of the instrument's pin as well as strength of the welded plate (Figure 16).

On other hand, optimal welding parameters lead to a higher strength welded plate, rather than an extended strong plate. Given data reported by Teri, it is worth noting that changes in the linear movement speed need to be along with alterations in the rotation speed. As can be seen from Table 3, experiments were carried out to study these two effective parameters and achieve a strong welded plate. Data in Table 3 also show the final strength of each welding line that is an 
TABLE 2: Optimal values predicted by the response level methodology model and alternative parameters.

\begin{tabular}{lccc}
\hline & - & Predicted & Alternative and available \\
\hline \multirow{3}{*}{ Criteria } & Rotation speed $(\mathrm{rpm})$ & $39 / 866$ & 800 \\
& Pin diameter $(\mathrm{mm})$ & $92 / 3$ & $9 / 3$ \\
& Linear velocity $(\mathrm{mm} / \mathrm{min})$ & $74 / 78$ & 80 \\
\hline Results & Holder diameter $(\mathrm{mm})$ & $26 / 14$ & $2 / 14$ \\
\hline
\end{tabular}

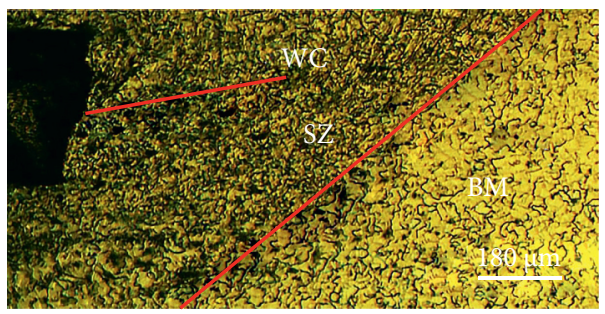

FIGURE 9: Microstructure of a welded specimen by nonoptimal parameters in the SZ and TMAZ region.
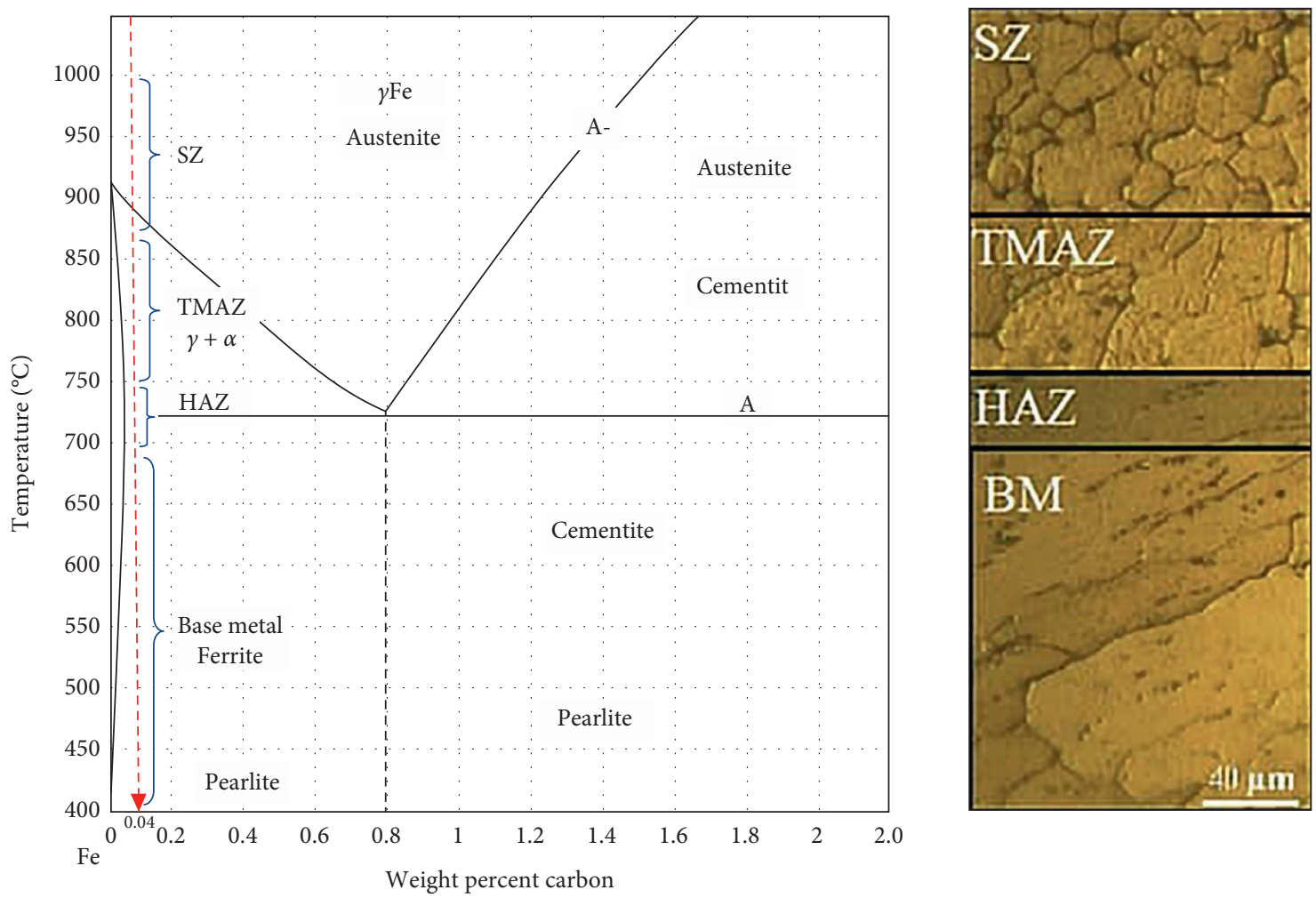

FIgURE 10: Carbon iron fuzzy diagram with different structures and different temperature rates.

average of two samples. Figure 17 illustrates the welded plate had the most strength in all studied rotational speeds when the linear movement speed was $50-10 \mathrm{~mm} / \mathrm{min}$. According to data, the highest strength has seen when the rotational speed ranged between 600 and 1000 rotations per minute. It is because of the high temperature generated caused by friction between the plate and the instrument in the mentioned rotational speed (Figure 18). Generally, the plate welded by taking some welding parameters into account cannot provide sufficiently strong for studying plasticity. Thus, five samples were selected and a combination of instruments' rotational speed and the linear movement speed causing the strongest welded plates was selected for each group. Table 4 shows these five tests exploited from Table 3.

Given diagrams, samples welded at the instrument's rotational and linear movement speeds ranging from 600 to 1000 rotations per minute, and $40-80 \mathrm{~mm} / \mathrm{min}$, respectively, are of the highest strength. It is worth noting that optimized parameters mentioned in Table 2 are also in this range. Point A shows these parameters. Results confirm the accuracy of 


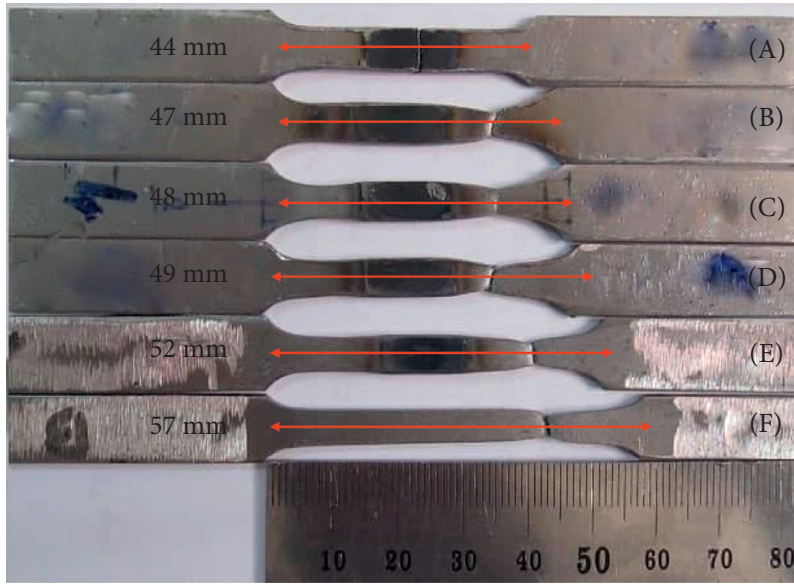

Figure 11: Welded tensile test specimens with acceptable parameters according to Table 2.
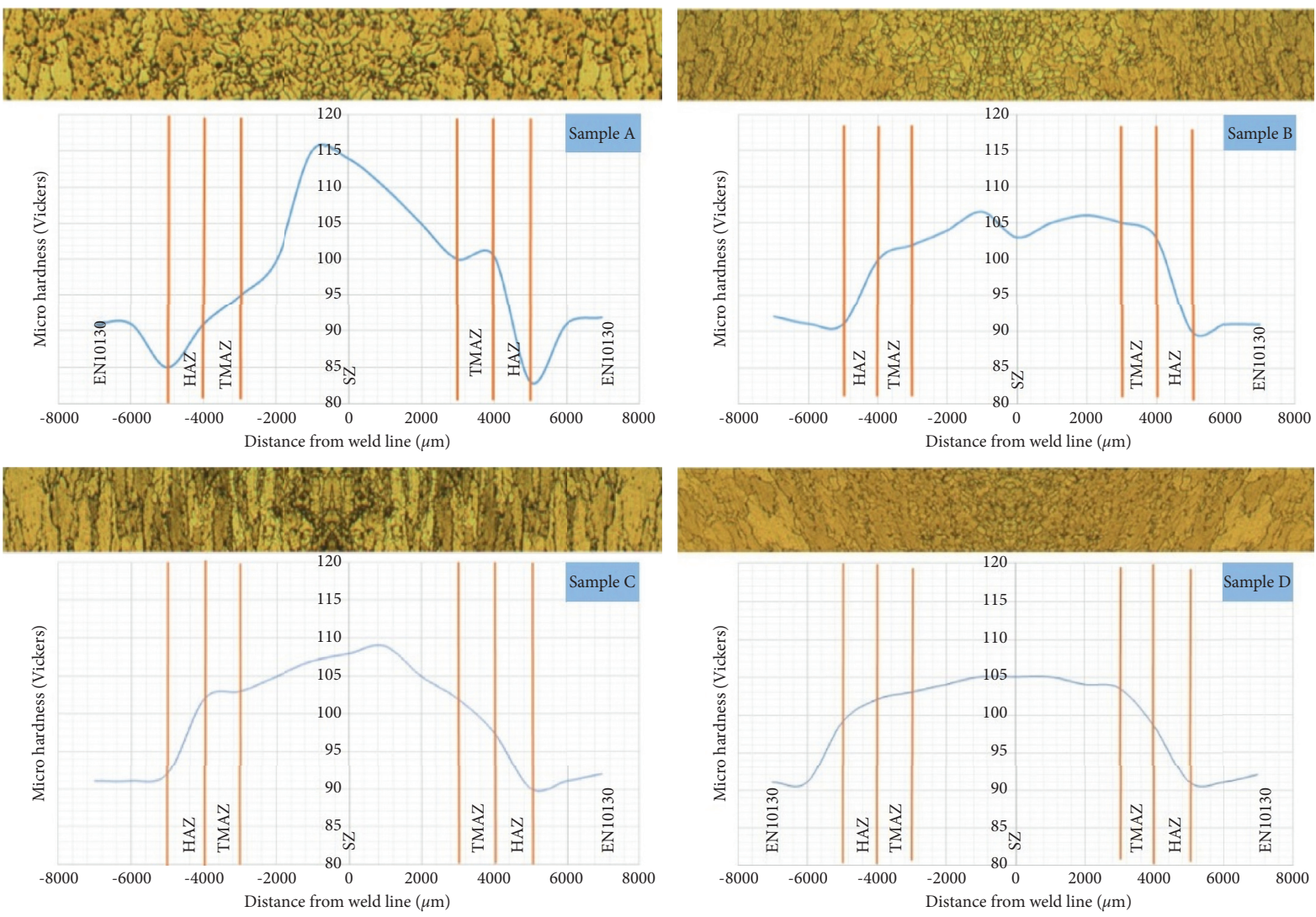

FIGURE 12: Results of welded microhardness samples A, B, C, and D.

TABLE 3: Welded parameters for microhardness test (a) to (d).

\begin{tabular}{|c|c|c|c|c|c|}
\hline Description & $\begin{array}{l}\text { Shoulder diameter } \\
(\mathrm{mm})\end{array}$ & $\begin{array}{c}\text { Pin diameter } \\
(\mathrm{mm})\end{array}$ & $\begin{array}{l}\text { Linear motion speed }(\mathrm{mm} / \\
\mathrm{min})\end{array}$ & $\begin{array}{l}\text { Rotation speed } \\
\quad(\mathrm{rpm})\end{array}$ & Sample \\
\hline More inlet heat & 14.2 & 3.9 & 50 & 1000 & A \\
\hline Less input heat & 14.2 & 3.9 & 100 & 500 & $\mathrm{~B}$ \\
\hline $\begin{array}{l}\text { Welding with acceptable } \\
\text { parameters }\end{array}$ & 14.2 & 3.9 & 100 & 1000 & $\mathrm{C}$ \\
\hline $\begin{array}{l}\text { Welding with optimal } \\
\text { parameters }\end{array}$ & 14.2 & 3.9 & 80 & 800 & $\mathrm{D}$ \\
\hline
\end{tabular}


Sample (a)

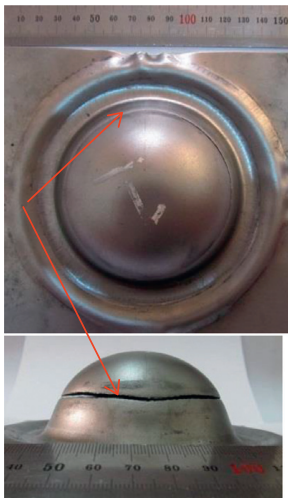

(a)
Sample (b)

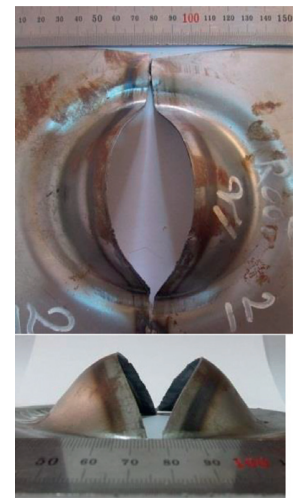

(b)
Sample (c)

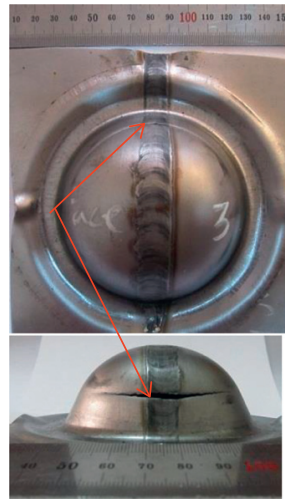

(c)
Sample (d)

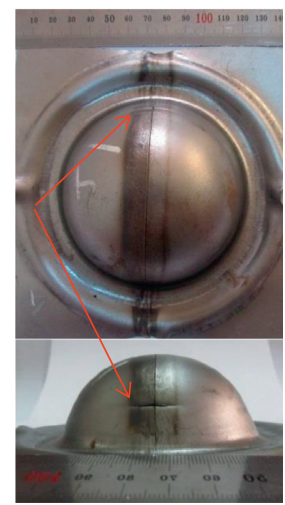

(d)

FIGURE 13: Dome-limited height test specimens. (a) Raw sheet ST14. (b) Welded specimen with nonoptimal parameters. (c) Welded specimen with optimal welding procedure parameters. (d) Welded sample with optimal welding root parameters.

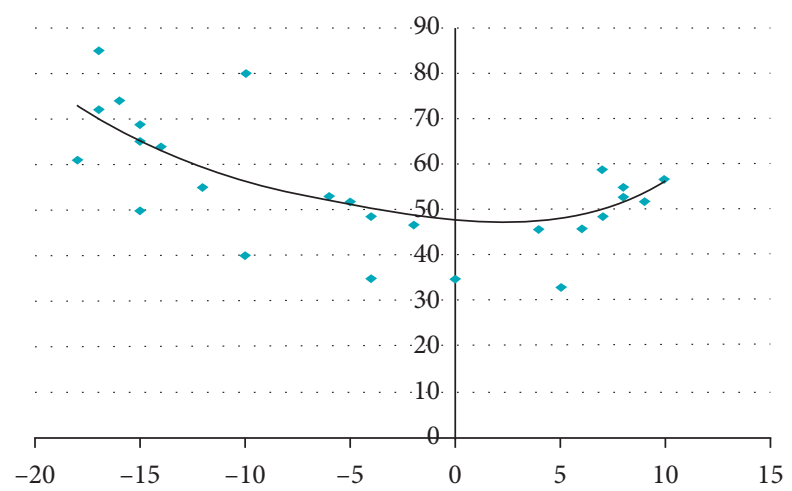

FIGURE 14: Ductility limit ST14 welded with a thickness of $1.5 \mathrm{~mm}$ by turbulent friction welding process.

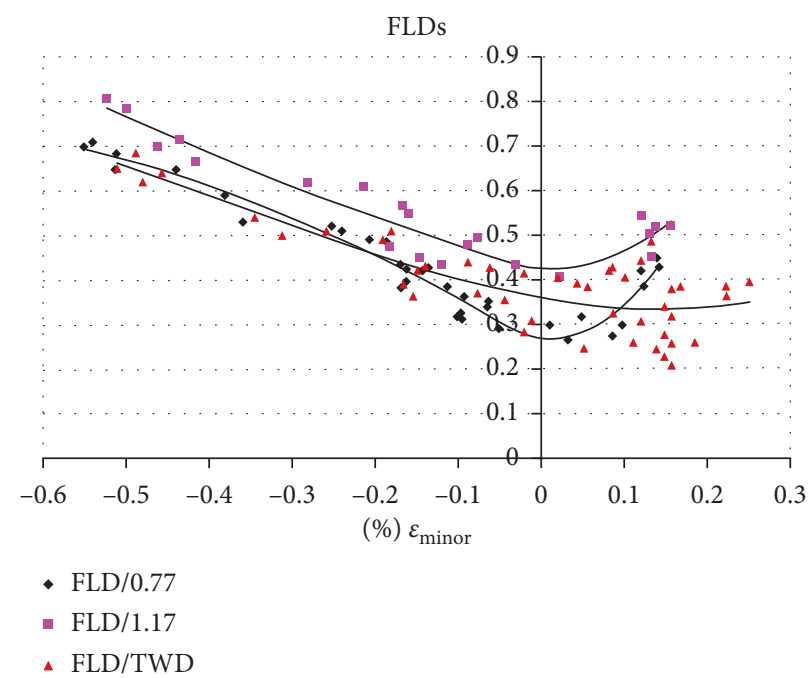

FIGURE 15: Ductility limit of ST14 steel with nonuniform thicknesses and their comparison with the welded specimen. 


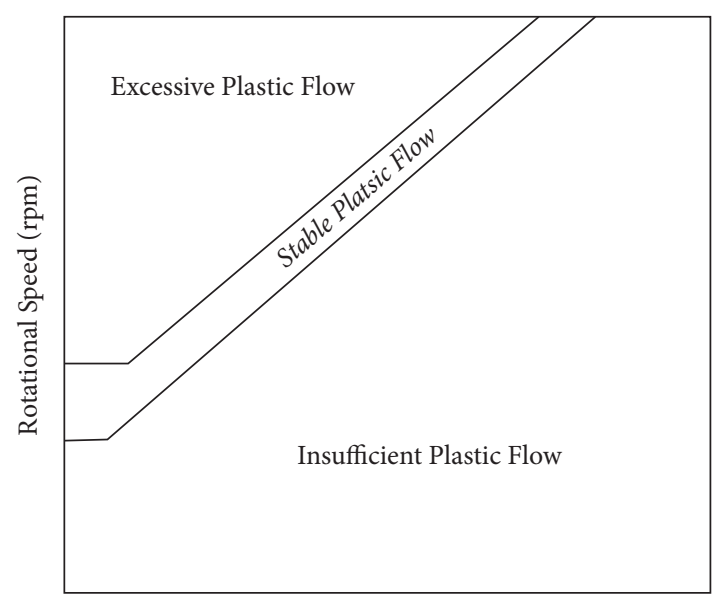

Travel Speed

(a)

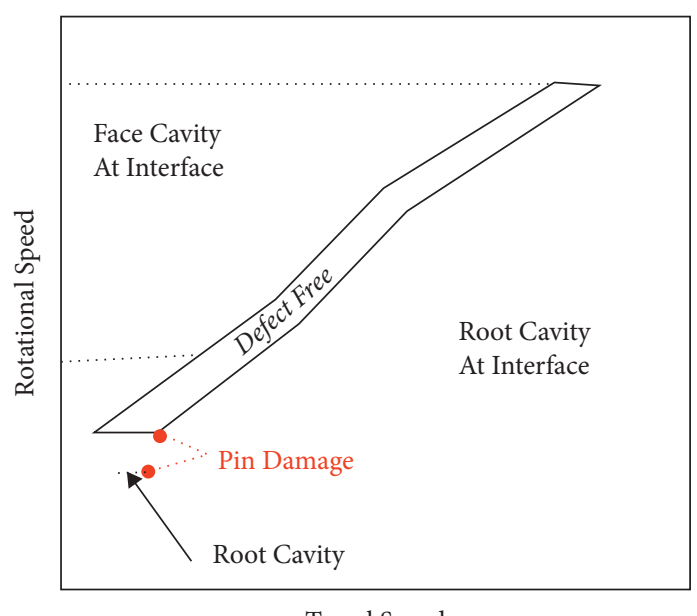

Travel Speed

(b)

Figure 16: The relationship between rotational speed and linear velocity is suitable for creating a fault-free connection. (a) The acceptable area of the relationship between rotational speed and linear motion speed in the connection of 6063 aluminum alloy and S45C steel and (b) types of defects created in different areas of section.

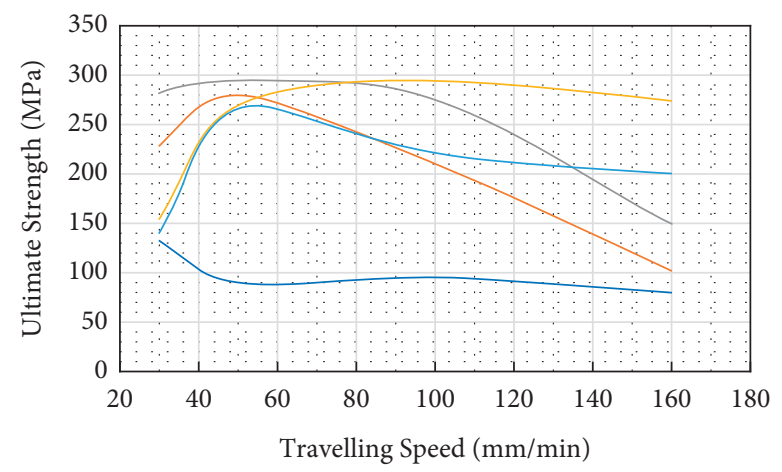

$$
\begin{array}{lr}
-500 \mathrm{rpm} & -1000 \mathrm{rpm} \\
- & 600 \mathrm{rpm} \\
- & 800 \mathrm{rpm}
\end{array}
$$

FIGURE 17: The final strength in terms of variable forward velocity and constant rotational speed.

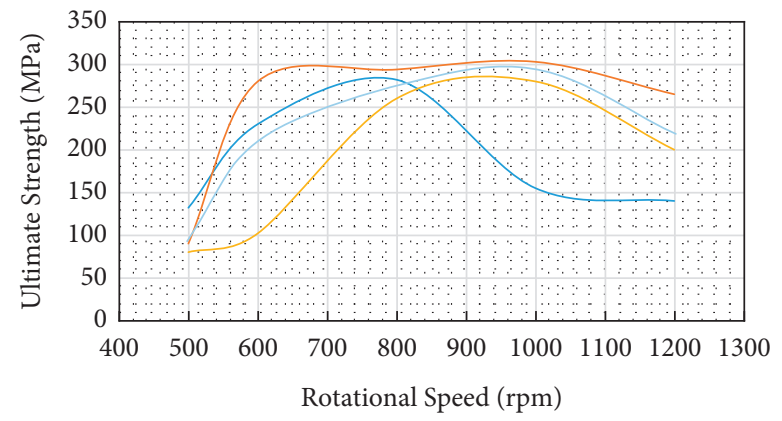

$$
\begin{array}{ll}
- & 30 \mathrm{~mm} / \mathrm{min} \quad 160 \mathrm{~mm} / \mathrm{min} \\
& 50 \mathrm{~mm} / \mathrm{min} \\
& 100 \mathrm{~mm} / \mathrm{min}
\end{array}
$$

FIgURE 18: The final strength in terms of variable rotational speed and fixed linear velocity. 
TABLE 4: Five sets of samples selected.

\begin{tabular}{|c|c|c|c|c|c|c|}
\hline Test number & $\begin{array}{c}\text { Classification } \\
\text { of tests }\end{array}$ & $\begin{array}{l}\text { The speed } \\
\text { of the era }\end{array}$ & $\begin{array}{c}\text { Linear motion } \\
\text { speed }(\mathrm{mm} / \mathrm{min})\end{array}$ & $\begin{array}{l}\text { Pin diameter } \\
(\mathrm{mm})\end{array}$ & $\begin{array}{c}\text { Shoulder } \\
\text { diameter }(\mathrm{mm})\end{array}$ & $\begin{array}{c}\text { Ultimate } \\
\text { strength }(\mathrm{MPa})\end{array}$ \\
\hline 1 & $\mathrm{~A}$ & 500 & 31.5 & 3.9 & 14.2 & 132 \\
\hline 6 & B & 600 & 50 & 3.9 & 14.2 & 190 \\
\hline 10 & $\mathrm{C}$ & 800 & 50 & 3.9 & 14.2 & 298 \\
\hline 14 & $\mathrm{D}$ & 1000 & 100 & 3.9 & 14.2 & 294 \\
\hline 18 & $\mathrm{E}$ & 1200 & 100 & 3.9 & 14.2 & 265 \\
\hline
\end{tabular}

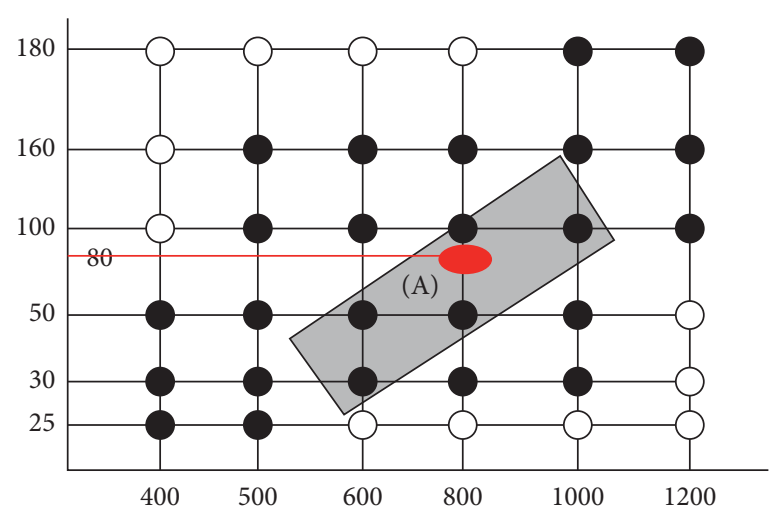

FIgURE 19: Suitable area for selecting the rotational speed and linear velocity of the tool for the production of welded sheets.

factors, experiments, resultant function, and, last but not the least, results after optimization. In addition, selected samples create an area consisting of rotational and linear movement speeds that are in agreement with those studied in Figure 19.

\section{Conclusion}

The FSW is used to connect ST14 plates of $1.5 \mathrm{~mm}$ thickness. By applying principles of friction stir welding, it is possible to weld plates without any burst, tunnel holes, incomplete penetration of the root into the welded surface, and protrusion of material. Response surface methodology is considered an effective way to optimize studied factors. It measures three-dimensional diagrams or the effect of the response surface of each factor on the objective function. Research findings showed that parameters such as rotational speed, linear movement speed, the diameter of the shoulder, and the diameter of the instrument's pin have the most effect on the strength of welded plates, respectively. Results showed that rotational speed (866.39 rotations per minute), linear movement speed $(78.74 \mathrm{~mm} / \mathrm{min})$, the diameter of the instruments' shoulder $(14.26 \mathrm{~mm})$, and diameter of the pin $(3.92 \mathrm{~mm})$ serve as the optimal values for welding ST14 plates with the highest strength.

An error of 1.092 was found between optimization results and experimental data after carrying out experimental tests on mechanical properties of samples using the normal stretching test. Results suggest the efficiency of the model as well as data on the optimization prediction. Findings showed that the strength of stirred area is higher in welded plates than the base metal. On both sides of the welding line, the area influenced by the temperature has lower strength than the base metal due to the presence of coarse grains. The least strength was recorded for the base metal influenced by temperature in the nonoptimal connection. The FSW makes it possible to achieve the optimal welded ST14 plates. In other words, there is no difference between data obtained from the height test of the dome section as well as the forming limit diagram of a welded plate and a raw ST14 plate. Data of various experiments such as experiment design, stretching test, height test of the dome section, as well as forming limit diagram all point out the effect of friction stir parameters on the quality and properties of connections. To put it simply, the value of one parameter depends on that of others. As a result, there is a certain limit to developing an efficient connection. Applying the FSW (FSW) for steel is economic, providing that a steel plate of less than $10 \mathrm{~mm}$ thickness with a long connection area is welded or it is done for a steel plate of high thickness.

$\begin{array}{ll}\text { Abbreviations } & \\ \text { Angle of deviation: } & \alpha \\ \text { Compensation angle: } & \Theta \\ \text { Friction coefficient: } & \mu \\ \text { Thermal efficiency: } & \alpha \\ \text { The main strain: } & \text { E1 } \\ \text { Substrain: } & \text { E2 } \\ \text { Input power: } & Q \\ \text { Pressure: } & P \\ \text { The } & \end{array}$

The rotational speed of the tool: $W$ Linear motion speed of the tool: $V$ Shoulder radius: $R$ Melting point: $\quad T m$. 


\section{Data Availability}

Requests for access to these data should be made to the corresponding author (m.afshari@aut.ac.ir).

\section{Conflicts of Interest}

The authors declare that there are no conflicts of interest regarding the publication of this paper.

\section{References}

[1] A. Von Strombeck, G. Çam, J. F. Dos Santos, V. Ventzke, and M. Koçak, "A comparison between microstructure, properties, and toughness behavior of power beam and friction stir welds in Al-alloys," in Proceedings of the TMS 2001 Annual Meeting Aluminum, Automotive and Joining, S. K. Das, J. G. Kaufman, and T. J. Lienert, Eds., pp. 249-264, TMS, New Orleans, Louisiana, USA, February 2001.

[2] G. Çam and G. İpekoğlu, "Recent developments in joining of aluminium alloys," International Journal of Advanced Manufacturing Technology, vol. 91, no. 5-8, pp. 1851-1866, 2017.

[3] N. Kashaev, V. Ventzke, and G. Çam, "Prospects of laser beam welding and friction stir welding processes for aluminum airframe structural applications," Journal of Manufacturing Processes, vol. 36, pp. 571-600, 2018.

[4] G. İpekoğlu, T. Küçükömeroğlu, S. M. Aktarer, D. M. Sekban, and G. Çam, "Investigation of microstructure and mechanical properties of friction stir welded dissimilar St37/St52 joints," Materials Research Express, vol. 6, no. 4, Article ID 046537, 2019.

[5] G. Çam and G. İpekoğlu, "Effects of use of higher strength interlayer and external cooling on properties of friction stir welded AA6061-T6 joints," Science and Technology of Welding \& Joining, vol. 19, no. 8, pp. 715-720, 2014.

[6] G. İpekoğlu and G. Çam, "Effects of initial temper condition and post-weld heat treatment on the properties of dissimilar friction-stir-welded joints between AA7075 and AA6061 aluminum alloys," Metallurgical and Materials Transactions A, vol. 45A, no. 7, pp. 3074-3087, 2014.

[7] T. Küçükömero, S. M. Aktarer, and G. Çam, "Investigation of mechanical and microstructural properties of friction stir welded dual phase (DP) steel," IOP Conference Series: Materials Science and Engineering, vol. 629, Article ID 012010, 2019.

[8] Q. U. Huang and C. X. Gao, G. Yang, Tensile and compressive properties of AISI 304L stainless steel subjected to equal channel angular pressing," Materials Science and Engineering, vol. 475, pp. 205-216, 2006.

[9] M. Jafarzadegan, A. H. Feng, T. Saeid, J. Shen, and H. Assadi, "Microstructural characterization in dissimilar friction stir welding between 304 stainless steel and st37 steel," Materials Characterization, vol. 74, pp. 28-41, 2012.

[10] M. Burak and C. Meran, "The effect of tool rotational and traverse speed on friction stir weldability of AISI 430 ferritic stainless steels," Materials and Design, vol. 33, pp. 376-383, 2012.

[11] R. Ueji, H. Fujii, L. Cui, A. Nishioka, K. Kunishige, and K. Nogi, "Friction stir welding of ultrafine grained plain lowcarbon steel formed by the martensite process," Materials Science and Engineering, vol. 423, pp. 324-330, 2012.

[12] S. M. S. Kolbadi, M. Safi, A. Keshmiri, S. S. Kolbadi, and M. Mirtaheri, "Explosive performance assessment of buried steel pipeline," Advances in Civil Engineering, vol. 2021, Article ID 6638867, 24 pages, 2021.

[13] S. M. S. Kolbadi, H. Piri, K. Ali, S. M. S. Kolbadi, and M. Mirtaheri, "Nonlinear seismic performance evaluation of flexural slotted connection using endurance time method," Shock and Vibration, vol. 2020, Article ID 8842230, 15 pages, 2020.

[14] G. Xiao, K. Song, Y. He et al., "Prediction and experimental research of abrasive belt grinding residual stress for titanium alloy based on analytical method," International Journal of Advanced Manufacturing Technology, vol. 115, 2021.

[15] W. M. Thomas, E. D. Nicholas, J. Needham, M. Murch, P. Templesmith, and C. Dawes, "Friction stir butt welding," International Patent Application. No. PCT/GB92/02203, 1991.

[16] R. S. Mishra and Z. Y. Ma, "Friction stir welding and processing," Materials Science and Engineering: R: Reports, vol. 50, no. 1-2, pp. 1-78, 2005.

[17] T. Li, Z. Dai, M. Yu, and W. Zhang, "Numerical investigation on the aerodynamic resistances of double-unit trains with different gap lengths," Engineering Applications of Computational Fluid Mechanics, vol. 15, no. 1, pp. 549-560, 2021.

[18] C. Liu, X. Gao, D. Chi, Y. He, and M. Liang, H. Wang and $\mathrm{H}$. Wang, On-line chatter detection in milling using fast kurtogram and frequency band power," European Journal of Mechanics-A: Solids, vol. 90, Article ID 104341, 2021.

[19] H. Deng, Y. Chen, Y. Jia et al., "Microstructure and mechanical properties of dissimilar NiTi/Ti6Al4V joints via back-heating assisted friction stir welding," Journal of Manufacturing Processes, vol. 64, pp. 379-391, 2021.

[20] J. Xie, Y. Chen, L. Yin, T. Zhang, S. Wang, and L. Wang, "Microstructure and mechanical properties of ultrasonic spot welding TiNi/Ti6Al4V dissimilar materials using pure $\mathrm{Al}$ coating," Journal of Manufacturing Processes, vol. 64, pp. $473-480,2021$.

[21] R. Crawford, A mechanical study of the friction stir welding process, Ph.D. Dissertation, Graduate School of Vanderbilt University, Nashville, TN, USA, 2006.

[22] M. Afshari, A. Alireza Fallahi, S. Iraj, and A. Alavi, "Effective parameters on cladded plate delamination during pressure vessels head manufacturing by FEM and DOE," Turkish Journal of Computer and Mathematics Education (TURCOMAT), vol. 12, no. 14, pp. 1789-1801, 2021.

[23] J. Zhang, A. D. Shaw, C. Wang et al., "Aeroelastic model and analysis of an active camber morphing wing," Aerospace Science and Technology, vol. 111, Article ID 106534, 2021.

[24] B. Zhang, Y. Chen, Z. G Wang, J. Li, and H. Ji, "Influence of mach number of main flow on film cooling characteristics under supersonic condition," Symmetry, vol. 13, no. 1, 2021.

[25] A. A. Mousavi, C. Zhang, S. F. Masri, and G. Gholipour, "Structural damage detection method based on the complete ensemble empirical mode decomposition with adaptive noise: a model steel truss bridge case study," Structural Health Monitoring, 2021.

[26] M. Hajimirsadeghi, M. Mirtaheri, A. P. Zandi, and M. A. H. Ardebili, "Experimental cyclic test and failure modes of a full scale enhanced modular steel plate shear wall," Engineering Failure Analysis, vol. 95, pp. 283-288, 2019. 